\title{
Self-concept, interpersonal processes, exploratory and health risk behaviors in adolescents - a study regarding student engagement with school
}

Mugur Ciumăgeanu, Raluca Sfetcu, Florina Suditu

\begin{abstract}
Adolescence is by definition an "age of risk", irrelevant if you substantiate such a claim experientially or empirically. Mid-adolescence is the period where the processes of both neural and socio-emotional maturation are linked with an increase in both exploratory and health-risk behaviors. The present study, using a cross-sectional approach, investigates aspects of intra and interpersonal processes in relationship to risk behaviors and risk perceptions, and tries to link these constructs to student engagement. The study-sample consisted of $1079^{\text {th }}$ to $12^{\text {th }}$ graders from three Romanian counties. The measures used were self-reports, appraising intrapersonal configurations (Beck Self-Concept Test), interpersonal problems (Inventory of Interpersonal Problems), and social and school adjustment (Social Adjustment Scale - Self Report). Risk behaviors and perception were measured with the Adolescent Exploratory and Risk Behavior Rating Scale (AERRS). The main research finding was that student engagement with school is in direct relationship with a better self-concept, more exploratory risk behaviors and a more adequate social adjustment. A puzzling result, explained probably better by the dual-process theory of behavior, is the relationship of risk perception to selfconcept and interpersonal problems (id est - a greater risk perception is correlated with a more fragile self-concept and more interpersonal problems).
\end{abstract}

Keywords: adolescence; risk behaviors; self-concept; student engagement with school; interpersonal functioning.

\section{Introduction}

There is a large body of research that links adolescence with risk and risk behavior. Although risk behaviors are also present in different displays during adulthood, adolescence is the one to be referred as the "age of risk". Defined generally, risk implies three components 1) exposure to both potential rewards and costs; 2) awareness of the likelihood of the potential outcomes; and 3) uncertainty about these outcomes (Holton, 2004). Neuroeconomics and its outlook on the developing brain of the adolescents situates risk behavior in the general framework of decision-making processes, implying a proclivity towards risky choice, an increased sensitivity to gains and losses and a graduate increase in social perspective taking (Van Duijvenvoorde \& Crone, 2013).

Such comprehensive and integrative perspectives on risk behaviors (and their inner drives) are generally new. Traditionally, the focus of both theory and preventive interventions relied on behavioral studies and models, intra-personal or inter-personal features of the risk-experience being regarded more as epiphonema of the overt

\footnotetext{
- MD, Lecturer, Department of Psychology, West University of Timișoara, mugur.ciumageanu@e-uvt.ro

- PhD, Associate Professor, Spiru Haret University Bucharest, Raluca.sfetcu@hotmail.com

- MA student, Department of Psychology, West University of Timișoara, florina.suditu94@e-uvt.ro
} 
behavioral display. Classical authors in the field, as Arnett (1992) or Jessor (1992), shaped a developmental and psychosocial framework for understanding the construct of risk behavior in adolescence, but recent additions, both empirical and theoretical, expand the focus and shift more on inner drives and dynamics.

The present study, even if not harmonized with neuroeconomics or with modern research paradigms (relying on neuroimagery or on multimethod assessment), contributes with an eclectically and open approach, including a socio-clinical perspective on this psychosocial phenomenon. In this first part of our article , we intend to outline the behavioral aspects of risk behavior, expanding afterwards the outlook towards neuro-developmental approaches and socio-cognitive theories. The introduction part will be continued with some inquires on the pragmatic use of theory and its possible application in the field of engagement in school.

\section{Two types of behaviors?}

From an observational vantage point, there are at least two large families of behaviors that delineate the categories of risk behaviors. The obvious "dangerous" and "maladaptive" side, such as addictive behaviors, reckless conducts or aggressive displays, fall under the coverage of health risk behaviors. On the other side, equally risky behavior, but with more "adaptive" or at least "pro-social" outcomes, such as standing up for someone's rights or asking a person for a date, can be coined exploratory risk behaviors. Although there are no clear-cut boundaries between the two categories, especially because of the personal and interpersonal outcomes of these conducts, which can largely vary, we go along with the recommendation of the literature, and use the descriptors as such.

Health risk behaviors - the realm of health risk behaviors, originating mainly in adolescence, covers conducts linked over the life course with illness, injury, mortality or other negative outcomes. In the juvenile stage, compared to the adult one, there is a high co-occurrence of delinquency, substance use and sexual risk behavior, to name only the main displays of such behaviors, with a usual clustering of such behaviors and their possible increase and subsequently decline towards the adult period, with a peak in midadolescence - Doran, et al, (2012); Hair, et al, (2009); Jackson, Sweeting, \& Haw, (2012). Two theoretical approaches attempt to explain this aggregation of risk behavior in adolescence. The gateway theories imply that one form of risk behavior leads to the potential experimentation of other behaviors, either due to increased exposure or to the lowering of risk perception for other risk conducts (Pudney, 2003). The second theoretical approach, considered a classic psychosocial theory, is Jessor's problem behavior theory. Jessor - for an overview, read Jessor, (2016) - posits that problem behaviors rise at the boundaries between social conventions and the interplay of risk and protective factors. Jessor's theory represents today a framework that explains adolescent behavior and health in a developmentally informed manner. Both theories received some support from longitudinal studies, with the mention that co-occurrence and link between 
health risk behaviors diminish through adolescence, with multiple risk behavior usually being at the pinnacle in mid-adolescence (Hale \& Viner, 2016). Even if the two (somehow) complementary approaches draw attention on the aggregation of risk and problematic behaviors in adolescence, there is a cautionary tale attached to their conclusions preventive policies that target juvenile populations should not only focus on reducing risk factors (and behaviors), but more on promoting protective factors and supportive environments for safe experimentation (Jessor, Turbin, \& Costa, 1998). Especially problematic are policy actions aiming at the reduction of substance use (mainly soft drugs) in order to decrease the likelihood of hard drug consumption - there is a weak empirical support from gateway approaches that such policies are appropriate (Pudney, 2003).

Exploratory risk behaviors - although adolescence can be coined as an age of risk, it is also a critical period in acquiring both the adequate set of health relevant behaviors, habits, and life skills that allow adults to be functional and ever-adapting beings. A lot of the scientific effort has focused on health risk behaviors, suggesting that there is an implicit flaw of the adolescence ethos, its "correction" being a legitimate goal in order to yield the well-functioning adult. But there is also the other side of risk, irrelevant if one calls it prosocial, positive or exploratory. Risk behaviors that lead to potential skill acquisition and contribute to a positive psychosocial development are traditionally called exploratory risk behaviors (Irwin \& Vaughan, 1988). Terminology is diverse and still not steadied, although recent reviews insist upon the use of positive risk behaviors (Duell \& Steinberg, 2018). In the present study, we consider that the term 'exploratory risk behaviors' is more suited not only because it avoids the positive vs. negative dichotomy (placing all health risk behaviors in the maladaptive realm as 'negative'), but also because the term 'exploratory' is not related automatically and systematically to a semantic node that implies only positive outcomes.

\section{Some explanatory (theoretical) attempts}

The mere existence of such risk behaviors asks for an explanatory framework, both for their development and for their vanishing away. One simplistic opinion is that the vanishing (or, at least, diminishing) part belongs to the maturation process, seeing the presence of such behavior as a necessary "evil" in adolescence. Evolved learning theories attribute risk behaviors to a struggle for rationality. Even if general theoretical approaches such as the theory of reasoned action - TRA (Fishbein \& Ajzen, 2010) or the theory of planned behavior - TPB (Ajzen, 1991) try to explain human conduct, commonsense empirics say that adolescents are not "human" at all. Irrationality, impulsivity, enthusiasm, fad-dependence and other characteristics describe them better, both in positive, affectionate terms, but also in negative and maladaptive ones. As adults, we know that whole array of adolescent interactions experientially, and we are bystanders of this sometimes-exhausting rollercoaster. We demand, though, (from them) rationality and reason and center the largest corpus of studies dealing with risk behavior 
at this age on some variation of the EV (expectancy-value) approach, which is the "linchpin" of both TRA and TPB. The EV approach sees behavior as the result of a deliberative process that takes into account a series of antecedents such as outcome expectancies, feelings about the behavior as such, perceptions of other's intentions etc. In the meantime, behavioral intentions (BI) - and their explicit statements - are seen as a legitimate goal that can shape future behaviors (Gollwitzer, 1999).

Including this reason-demanding conditions, both TRA and TPB, or derived theories, prove useful in explaining virtually all features pertaining to health and ill-health behaviors and health behavior change - for a review, see Armitage \& Conner (2000). The only field these theories fail to have enough predictive power is adolescence - both in health (risk) behaviors but possibly also in the area of the exploratory ones (de Ridder \& de Wit, 2006; Reyna \& Farley, 2006).

This is one of the reasons that researchers started to include dual-process formulations in the attempts to explain the peculiarities of risk behaviors in adolescence. Dual-process theories rely on the heuristic-systematic model of action (for an overview, see Sherman, Gawronski, \& Trope, 2014), assuming two independent informationprocessing systems that work in parallel: one rational, central system that implies effortful and intentional processing, which could be functioning based on EV rules; and a second, peripheral system, which involves more superficial processing based largely on heuristics, which is quick and experiential. For the moment, there is a general agreement that young people use more heuristic systems than adults, and that the dual processing framework is more appropriate in describing and explaining adolescent behavior (Gibbons, Houlihan, \& Gerrard, 2009).

Dual process theories are also in line with neurodevelopmental theories and confirm the swiftness of reactions and changes that occur in the interpersonal and intrapersonal field for the majority of adolescents. Normative adolescent impulsivity, risk-taking and substance-use are associated with changes in brain development suggestive of synaptic refinement and myelination, especially pertaining the prefrontal and limbic system (Casey \& Jones, 2010). The neural regions that make adolescents prone to risk-taking are the very one that, through maturation, seem to limit the risk-taking behavior, explaining the decline of such behaviors at the beginning of adult life (for the role of the ventral striatum, see Telzer, et al, 2013).

Paralleling the dynamics of (risk) behaviors, the self of the adolescent is also thorned between rationality and heuristic passion. The self is both a construct and a process (but more an organizing process), that mediates both intrapersonal and interpersonal processes (Heinz, Bermphol, \& Frank, 2012). Adolescence represents a key developmental age for the everlasting representational negotiation process that constitutes self-image and self-esteem structuring. Mid-adolescence is the busiest construction site, where new cognitive developments set the stage for more mature and adaptive self-processes (for a synthesis, see Harter, 2012). Hormonal and neurological maturation processes overlap with the intensification of key developmental contexts 
such the spiraling of social and emotional experiences and the increase of influence of peers and social contexts (Crone \& Dahl, 2012). The development of a mature selfconcept depends largely on comparative interpersonal processes, focused on friends and peers mainly, with impact on the neural functioning (Romund, și alții, 2017).

As a synthesis of this short incursion in theories, risk behaviors are best explained in the larger context of a social and neural maturation process based mainly on a disbalance between reasoned actions and heuristic ones. Intrapersonal and interpersonal processes are part of this formulation, and not by-products of the adaptation struggle of adolescents.

\section{Student engagement with school vs. risk behaviors}

The focus on risk/problem behavior of adolescents is of uttermost importance when we take into account the phenomenon of student engagement with school. Comprehensive and multidimensional analysis of the student engagement construct implies a relationship between self-regulatory processes and academic, social and emotional outcomes (risk behaviors included), postulating a mediating role of different forms of engagement (cognitive, behavioral and emotional) between the two aforementioned categories - see Appleton, Christenson, \& Furlong, 2008.

Our study uses the generic framework of the Self-processes Model applied to Educational Settings (Appleton, Christenson, \& Furlong, 2008, p. 380), advancing several research assumption (see Figure 1): 1) self-concept, as identified by the Beck SelfConcept Scale (BSCS, see below), is a generic descriptor of self-system processes, and it hypothetical influences both risk-perception and school adjustment; 2) social adjustment, as described by the Social Adjustment Scale - Self-report (SAS-SR, see below), approximates some aspects both of the autonomy/relatedness component, but also of the behavioral engagement as dimensions of the student engagement with school; 3 ) risk perception is a main feature of the cognitive engagement component (with a possible effect on both academic and social/interpersonal outcomes); 4) interpersonal problems (as measured by the Inventory of Interpersonal Problems - IIP, see below) can be considered an outcome variable in the social outcomes domain of the model, partially explained both ty risk perception and school adjustment (as we will try to prove in a regression analysis).

The choice of the model complied also with some theoretical concerns, which we will explore in further studies, especially related to a dual processes approach in explaining both exploratory and health risk behaviors and their link to school engagement. The present study focuses mainly on drafting some correlational links between intrapersonal processes (as the consolidation of self-concept) and interpersonal processes (as social adjustment and relational features), and their general links with risk perception and behavior. 


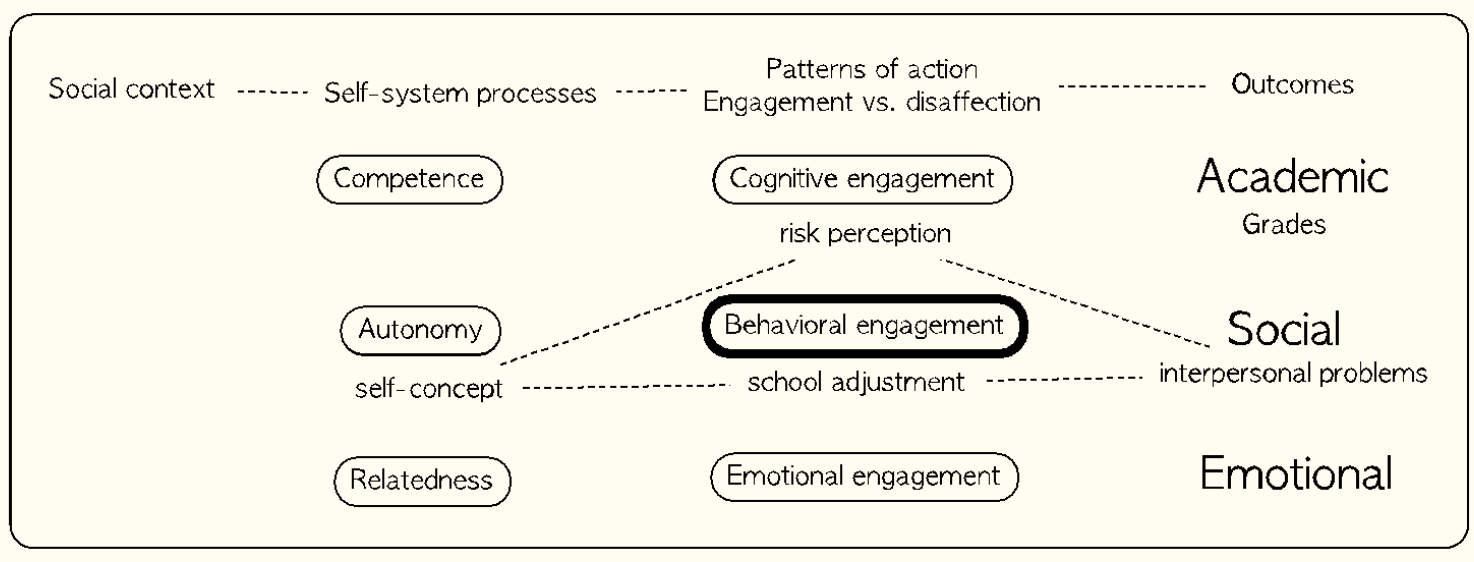

Figure 1 - Putative links between components and dimensions of the Self-processes Model applied to Educational Settings - Appleton, Christenson, \& Furlong (2008), as used in the present study. Emotional outcomes and emotional engagement features were not included in the present study.

\section{Method}

The main objective of our study is to assess the dynamics between two categories of risk behaviors (exploratory vs. health risk) in relation with intrapersonal (self-concept) and interpersonal processes (social adjustment \& interpersonal functioning). The primary hypothesis is that the engagement with school (even in the context of the COVID-19 pandemic) is correlated with increased risk perception, higher exploratory risk behaviors and a more positive self-concept.

\subsection{Sample}

The study was conducted in three local schools from three different Romanian counties, Timis,, Gorj and Dolj. Subjects were all consenting $9^{\text {th }}$ to $12^{\text {th }}$ graders $(n=107)$, participating voluntary with no extra incentives. The sample was predominantly feminine $(n=93)$, with ages ranging from 14 years $(n=4)$ to 18 years $(n=38)$, the majority of them being around $17(n=41)$. Most students reported that they live with their parents $(n=94)$, only 4 of them reporting that they live alone. One special comment is that the data collection took place during the partial lock-down due to the COVID-19 pandemic (MayJune 2020), with all the students being enrolled in online courses.

\subsection{Procedure}

The present study has a cross-sectional, correlational design. The questionnaires were administered online in a Google-forms format. Apart from ensuring confidentiality, no special validity check was performed. All data were analyzed using SPSS version 22.00, generating descriptive and correlational reports. For each of the self-report instruments, alpha coefficients (Cronbach's Alpha) were calculated for both the scales and the subscales. A regression analysis was performed in order to test the link between social adjustment and risk perception, on the one hand, and the intensity of interpersonal problems, on the other hand. 


\subsection{Measures}

All measures used for the present study were self-reports, including a self-reported global academic attainment rating. Basic socio-demographic data were obtained, including the profile of the school and the background of the student's family (urban vs. rural). The self-report measures used in the study were:

Adolescent Exploratory and Risk Behavior Rating Scale (AERRS) - (Skaar N. R., 2009) - the scale explores both participation in risk behaviors, and, on the same 43 items, risk perception of both health and exploratory risk behavior. AERRS uses for risk behaviors a Likert scale from 1 (never) to 4 (often), with higher scores meaning increased participation in risk behavior. For the risk perception scale, the instrument uses a Likert from 1 (not risky) to 4 (very risky), with higher scores reflecting a higher perception of risk. The author reports solid coefficient alphas of .93, .96, and .89 for the total score, respective health risk and exploratory risk scale. For the present study, we obtained similar alphas, ranging from .912 to .86. The author published more recently an abbreviated screening instrument based on the AERRS (Skaar, Christ, \& Jacobucci, 2014), but there is a shift from exploratory risk behaviors towards prosocial risk behaviors, which was not in agreement with our study, and we decided to keep the initial form of the scale. The scale was translated into Romanian by the first and third author special for this study. Back-translation was assured by an independent translator and the correspondence of items was evaluated by the first author.

Beck Self-Concept Test (BSCT) - (Beck, et al, 1990) is a 25-item measure that invites the respondents to compare themselves to other people they know using a five-point ordinal semantic differential scale, with ratings from 25 to 125 . There are 16 items where higher scores mean a more negative self-concept - with (1) better than nearly anyone I know and (5) worse than nearly anyone I know. The other 9 items use an increasing degree of the characteristic. For the present study, we used a direct scoring system, with a higher score meaning a more negative self-concept. The coefficient alpha for the present study was .84, similar to the alpha reported in other studies. The scale was translated into Romanian by the first author as part of another study. Back-translation was assured by an independent translator and the correspondence of items was evaluated by the first author. As a special mention, BSCT was validated on clinical samples. Nowadays, its principal author (Aaron T. Beck) recommends for self-concept scales for adolescents the use of Beck Youth Inventories of Emotional and Social Impairment (BYI) - (Beck, Beck, \& Jolly, 2001). Since there are no known translation in Romanian of the BYI and due to possible copyright infringements, we decided to use the more classical measure, the BSCT.

Inventory of Interpersonal Problems (IIP) - (Horowitz, et al, 1988) - is an instrument used mainly in the therapeutical-clinical context, measuring distress associated to interpersonal sources. There are several variants of the instrument (with 64, 48, 40, 32 items), and a circumplex scoring system attached to it (developed initially by (Alden, Wiggins, \& Pincus, 1990). For the present study we used the 40 items form. IIP includes 
items that begin with the phrase "it is hard for me to..." and items that have as heading "things that you do too much". Each item is rated on a Likert scale ranging from 0 (not at all) to 4 (extremely). Eight specific interpersonal problems (or styles) result, that are arranged in a circular manner within a two-dimensional circumplex space. Octants include the following - Domineering, Vindicative, Cold, Socially Inhibited, Nonassertive, Overly Accommodating, Self-Sacrificing, and Intrusive/Needy. Several studies showed that both the long and shorter forms of the study have acceptable to good reliability, strong internal structure and good discriminant and convergent validity. Higher scores are indicative for an increased strain in interpersonal functioning. For the present study, we mention an excellent alpha coefficient of .923 for the entire scale, with alphas ranging from .68 to .91 for the subscales. The scale was translated into Romanian by the first author as part of another study, and the translation was revised by the third author. Backtranslation was performed by an independent translator and the correspondence of items was evaluated by the first author.

Social Adjustment Scale - Self-report (SAS-SR) (Weissman \& Bothwell, 1976) is a classic instrument assessing social adjustment. The scale was developed for clinical use, linking poor adjustment to proclivity towards emotional disorders both for adults and adolescents. The scale has 54 items, measuring expressive and instrumental performance over the past two weeks in six role areas: (1) work or study; (2) social and leisure activities; (3) relationships with extended family; (4) intimate relationship; (5) parental role; (6) role within the family unit, including perceptions about economic functioning. For adolescents, there is a mention to skip the non-relevant role areas. Even if shorter forms are in use (Gameroff, Wickramaratne, \& Weissman, 2011), we opted for the use of the initial scale, since it brings more detail in school functioning, relevant for the engagement in school model we are testing. Internal consistency for the entire scale was acceptable (.784), in accordance with the research data. Alpha coefficient was higher for school functioning (>.85) subscale. For the SAS-SR, higher scores mean a poorer social adjustment and reduced role performance. Translation in Romanian of the scale was assured by the first and third author. An expert back-translated the scale in English and an external reviewer checked for the correspondence of items of the original scale with the translation.

\section{Results}

All responses were considered valid. The descriptive statistics regarding the scores for the scales are presented in table 1. At first glance, there is a (somehow) expected discrepancy between exploratory and health risk behaviors, in favor of the former. In other words, the students seem to engage (or report?) more exploratory risk behaviors than health risk ones. Taken into account the composition of the sample (mainly girls from "good" schools), as well as the context of the assessment (the COVID-19 restriction measures reducing the mobility and experimentation space for risk behaviors), such a discrepancy is not unexpected. 
Table 1 - Descriptive statistics on the instruments. Subscales of the IIP are not reported due to space restrictions. (AERRS = Adolescent Exploratory and Risk Behavior Rating Scale; SAS$S R=$ Social Adjustment Scale - Self-report; BSCT = Beck Self-Concept Test; IIP = Inventory of Interpersonal Problems).

\begin{tabular}{lcccccc}
\hline & & & & & & Std. \\
& $\mathrm{N}$ & Min & Max & \multicolumn{2}{c}{ Mean } & Deviation \\
\hline AERRS Risk Perception & 107 & 0 & 158 & 81.00 & 2.287 & 23.662 \\
$\begin{array}{l}\text { AERRS Risk Behavior } \\
\text { AERRS Health Risk }\end{array}$ & 107 & 0 & 113 & 49.93 & 1.929 & 19.954 \\
Behavior & 107 & 0 & 52 & 13.93 & 1.192 & 12.326 \\
AERRS Exploratory Risk & & & & & & \\
Behavior & 107 & 0 & 52 & 30.56 & 1.090 & 11.275 \\
SAS-SR School & 107 & 1 & 5 & 2.26 & .074 & .771 \\
SAS-SR Leisure & 107 & 1 & 4 & 2.38 & .060 & .621 \\
SAS-SR Family & 107 & 1 & 4 & 2.18 & .063 & .654 \\
SAS-SR Family unit & 107 & 1 & 5 & 1.50 & .088 & .915 \\
SAS-SR Total & 107 & 1 & 4 & 2.08 & .050 & .518 \\
BSCT Total & 107 & 25 & 106 & 66.46 & 1.133 & 11.722 \\
IIP Total & 107 & 40 & 149 & 91.36 & 2.250 & 23.275 \\
Valid N (listwise) & 107 & & & & & \\
\hline
\end{tabular}

If we analyze the inferential statistics, there are even more noteworthy results (see table 2). We assumed that an increased risk perception (as measured by AERRS) would correlate with fewer interpersonal problems and a more positive self-concept. As one can see, the results show the opposite - a higher risk perception is correlated with a more negative self-concept and with more interpersonal problems. Such a finding should be put into perspective. Self-concept is highly unstable and volatile in mid-adolescence, and self-reflective processes (such as risk perception) can be "protective" for some of the subjects in not engaging in risk behaviors, especially health risk behavior. If we refer to the dual-processes theory, increased risk perception for the subject means a possible engagement in deliberative processes (the 'reasoned' pathway), which prevents the engagement both in exploratory and health risk behaviors (the correlations between risk perception and exploratory or health risk behaviors are not statistically significant). The findings support also the alternative pathway of action (the heuristic one), by not linking health risk behaviors neither with interpersonal nor intrapersonal processes (see the non-significant correlation of the total behavior score measured by AERRS both with the total scores of BCST, SAS-SR and IIP). 
Table 2 - inferential statistics on the total scores of the scales (AERRS = Adolescent Exploratory and Risk Behavior Rating Scale; SAS-SR = Social Adjustment Scale - Selfreport; BSCT = Beck Self-Concept Test; IIP = Inventory of Interpersonal Problems).

\begin{tabular}{|c|c|c|c|c|c|c|}
\hline & & AERRS P & $\begin{array}{c}\text { AERRS } \\
\text { B }\end{array}$ & $\begin{array}{c}\text { SAS } \\
\text { Total }\end{array}$ & $\begin{array}{l}\text { BSCT } \\
\text { Total }\end{array}$ & IIP Total \\
\hline $\begin{array}{l}\text { AERRS } \\
\text { Perception Total }\end{array}$ & $\begin{array}{l}\text { Pearson } \\
\text { Correlation }\end{array}$ & 1 & -.065 & .182 & $.298^{* *}$ & $.436^{* *}$ \\
\hline $\begin{array}{l}\text { AERRS Behavior } \\
\text { Total }\end{array}$ & $\begin{array}{l}\text { Pearson } \\
\text { Correlation }\end{array}$ & & 1 & .038 & -.108 & -.015 \\
\hline SAS Total & $\begin{array}{l}\text { Pearson } \\
\text { Correlation }\end{array}$ & & & 1 & $.386^{* *}$ & $.624^{* *}$ \\
\hline BSCT Total & $\begin{array}{l}\text { Pearson } \\
\text { Correlation }\end{array}$ & & & & 1 & $.513^{* *}$ \\
\hline IIP Total & $\begin{array}{l}\text { Pearson } \\
\text { Correlation }\end{array}$ & & & & & 1 \\
\hline
\end{tabular}

On the other hand, if we look more in detail to the inferential statistics, we can see that there is a significant correlation between self-concept and exploratory risk behavior $\left(-.285^{* *}\right.$, significant at the 0,01 level 2 -tailed), which means that a more positive selfconcept correlates (only) with engagement in exploratory risk behaviors and not in health risk ones. Further inquiry into results confirm a more predictable pathway - a good self-concept is correlated both with a better social adjustment and a better interpersonal functioning (as can be inferred from table 2).

To test which of these variables have a significant impact on the interpersonal problems self-reported by the adolescents, we performed a regression analysis. The results of the regression indicated the two predictors explained $31.8 \%$ of the variance of IIP scores $(\mathrm{R} 2=.56, \mathrm{~F}(2,104)=24.21, \mathrm{p}=.000)$. It was found that SAS-SR significantly predicted IIP $(\beta=.47, \mathrm{p}<.00)$, as did AERRS-risk perception $(\beta=-.22, \mathrm{p}=.007)$.

\section{Limitations/discussion}

One of the obvious limitations of this study is related to the trustworthiness of responses. Direct questions relating to drug use, suicidal thoughts or interpersonal risk behaviors could lead to the suspicion of response biases. On the other hand, such questions could be considered upsetting or offensive. Studies on adolescence shed another light on this issue - under the protection of confidentiality, adolescents are neither upset, nor reluctant to answer straight, except a minority which is heavily traumatized or derived from very problematic backgrounds (Langhinrichsen-Rohling, et al, 2006). Our sample could be considered, if we take into account family background and school adjustment, rather straight answering, and supplementary validity inquiries were not performed, even if AERRS has such validity checks.

Being a preliminary study, we march along with the limitation of a convenience sample - our sample both disbalanced regarding gender and representativeness of the 
respondents for the entire adolescent population. Further studies, implying also an experimental (or, at least, quasi-experimental) approach and multimethod assessment procedures, would presumably bring more nuanced results regarding the interconnection of different risk behaviors and intra- and interpersonal processes.

Another limitation is related to the age of the respondents - we selected the midadolescence stage as the most representative level, since both risk-behaviors and intraand interpersonal processes are well represented. Future research should analyze both the early and late phases of adolescence, since personality and risk dynamics are very along the whole period.

\section{Conclusions}

Our research opens up some novel perspectives on risk behaviors in adolescents. The study of two different species of risk conducts (health risk vs. exploratory risk) shows a somehow different behavior of these constructs related to interpersonal and intrapersonal functioning. There is an urgent need to develop models that can predict better such behavioral reactions in adolescence, and dual-processes theory could provide more insights into a puzzling area of research. Regarding engagement with school, the process of increasing meta-cognitive abilities in the field of risk perception could lead, in the context of a good general social adjustment, to less interpersonal problems and an acceleration of the maturation process. In the meantime, programs aiming the increase in quality of school engagement should focus, especially in extraordinary times such the COVID-19 pandemic, on building up contexts for the deployment of exploratory (risk) behaviors.

\section{References}

Ajzen, I. (1991). The theory of planned behavior. Organizational Behavior and Human Decision Processes, $50,179-211$.

Alden, L. E., Wiggins, J. S., \& Pincus, A. L. (1990). Construction of circumplex scales for the inventory of interpersonal problems. Journal of Personality Assessment, 55(3-4), 521-536.

Appleton, J. J., Christenson, S. L., \& Furlong, M. J. (2008). Student engagement with school: Critical conceptual and methodological issues of the construct. Psychology in the Schools, 45(5), 369-386.

Armitage, C. J., \& Conner, M. (2000). Social cognition models and health behaviour: A structured review. Psychology \& Health, 15(2), 173-189.

Arnett, J. (1992). Reckless behavior in adolescence: A developmental perspective. Developmental review, 12, 339-373.

Beck, A. T., Steer, R. A., Epstein, N., \& Brown, G. (1990). Beck self-concept test. Psychological Assessment, 2(2), 191-197.

Beck, J. S., Beck, A. T., \& Jolly, J. (2001). Beck Youth Inventories ${ }^{T M}$ of Emotional and Social Impairment. The Psychological Corporation.

Casey, B., \& Jones, R. M. (2010, December). Neurobiology of the adolescent brain and behavior. Journal of the American Academy of Child and Adolescent Psychiatry, 49(12), 1189-1285.

Crone, E. A., \& Dahl, R. E. (2012). Understanding adolescence as a period of social-affective engagement and goal flexibility. Nature Reviews Neuroscience, (13), 636-650. 
de Ridder, D. T., \& de Wit, J. B. (2006). Self-regulation in health behavior: Concepts, theories, and central issues. In D. T. de Ridder, \& J. B. de Wit, Self-regulation in health behavior (pp. 1-24). Chichester: John Wiley \& Sons.

Doran, N., Luczak, S. E., Bekman, N., Koutsenok, I., \& Brown, S. A. (2012). Adolescent substance use and aggression - A review. Criminal Justice and Behavior, 39(6), 748-769.

Duell, N., \& Steinberg, L. (2018). Positive risk taking in adolescence. Child Development Perspectives, $0(0)$, $1-5$.

Fishbein, M., \& Ajzen, I. (2010). Predicting and changing behavior - The reasoned action approach. New York: Psychology Press.

Gameroff, M. J., Wickramaratne, P., \& Weissman, M. M. (2011). Testing the short and screener versions of the social adjustment scale - self-report (SAS-SR). International Journal of Methods in Psychiatric Research, 21(1), 52-65.

Gibbons, F. X., Houlihan, A. E., \& Gerrard, M. (2009). Reason and reaction: The utility of a dual-focus, dualprocessing perspective on promotion and prevention of adolescent health risk behaviour. British Journal of Health Psychology, 14, 231-248.

Gollwitzer, P. M. (1999). Implementation Intentions. The American Psychologist, 54(7), 493-503.

Hair, E. C., Park, J. M., Ling, T. J., \& Moore, K. A. (2009). Risky behaviors in late adolescence: Co-occurrence, predictors, and consequences. Journal of Adolescent Health, 45, 253-261.

Hale, D. R., \& Viner, R. M. (2016). The correlates and course of multiple health risk behaviour in adolescence. BMC Public Health, 16, 458.

Harter, S. (2012). The construction of the self: Developmental and sociocultural foundations. Second Edition. New York, NY: The Guilford Press.

Heinz, A., Bermphol, F., \& Frank, M. (2012). Construction and interpretation of self-related function and dysfunction in intercultural psychiatry. European Psychiatry, (Supplement n. 2), S32-S43. .

Holton, G. A. (2004). Defining risk. Financial Analysts Journal, 60(6), 19-25.

Horowitz, L. M., Rosenberg, S. E., Baer, B. A., Ureno, G., \& Villasenor, V. S. (1988). Inventory of interpersonal problems: Psychometric properties and clinical applications. Journal of Consulting and Clinical Psychology, 56(6), 885-892.

Irwin, C. E., \& Vaughan, E. (1988). Psychosocial context of adolescent development - Study group report. Journal of Adolescent Health Care, 9, 11S-19S.

Jackson, C., Sweeting, H., \& Haw, S. (2012). Clustering of substance use and sexual risk behaviour in adolescence: Analysis of two cohort studies. BMJ Open, 2, e000661.

Jessor, R. (1992). Risk behavior in adolescence: A psychosocial framework for understanding and action. $12,374-390$.

Jessor, R. (2016). The origins and development of problem behavior theory. Springer International Publishing Switzerland.

Jessor, R., Turbin, M. S., \& Costa, F. M. (1998). Protective factors in adolescent health behavior. Journal of Personality and Social Psychology, 75(5), 788-800.

Langhinrichsen-Rohling, J., Arata, C., O'Brien, N., Bowers, D., \& Klibert, J. (2006). Sensitive research with adolescents: Just how upsetting are self-report surveys anyway? Violence and Victims, 21(425-444).

Pudney, S. (2003, March). The road to ruin? Sequences of initiation to drugs and crime in Britain. The Economic Journal, 113, C182-C198.

Reyna, V. F., \& Farley, F. (2006). Risk and rationality in adolescent decision making. Psychological Science in the Public Interest, 7(1), 1-44.

Romund, L., Golde, S., Lorenz, R. C., Raufelder, D., Pelz, P., Gleich, T., ... Beck, A. (2017). Neural correlates of the self-concept in adolescence - A focus on the significance of friends. Human Brain Mapping, 38, 987-996.

Sherman, J. W., Gawronski, B., \& Trope, Y. (2014). Dual-process theories of the social mind. New York: The Guilford Press. 
Skaar, N. R. (2009). Development of the adolescent exploratory and risk behavior rating scale. (Unpublished $\mathrm{PhD}$ thesis): University of Minnesota.

Skaar, N. R., Christ, T. J., \& Jacobucci, R. (2014). Measuring adolescent prosocial health risk behavior in schools: Initial development of a screening measure. School Mental Health, 6, 137-149.

Telzer, E. H., Fuligni, A. J., Lieberman, M. D., \& Galvan, A. (2013). Ventral striatum activation to prosocial rewards predicts longitudinal declines in adolescent risk taking. Developmental Cognitive Neuroscience, 3, 45-52.

Van Duijvenvoorde, A. C., \& Crone, E. A. (2013). The teenage brain: A neuroeconomic approach to adolescent decision making. Current Directions in Psychological Science, 22(2), 108-113.

Weissman, M. M., \& Bothwell, S. (1976). Assessment of social adjustment by patient self-report. Archives of General Psychiatry, 33, 1111-1115. 